\title{
OCORRÊNCIA DA BRACATINGA (Mimosa scabrella BENTH.) EM BRACATINGAIS MANEJADOS E EM FLORESTAS SECUNDÁRIAS NA REGIÃO DO PLANALTO CATARINENSE ${ }^{1}$
}

\author{
Walter Steenbock ${ }^{2}$, Alexandre Siminski ${ }^{3}$, Alfredo Celso Fantini ${ }^{3}$ e Maurício Sedrez dos Reis ${ }^{3}$ \\ RESUMO - A bracatinga (Mimosa scabrella Benth.) é uma espécie florestal de múltiplo uso, típica do ecossistema \\ Floresta Ombrófila Mista, associado ao bioma Mata Atlãntica. Este estudo teve por objetivo comparar a estrutura, \\ a diversidade vegetal e a ocorrência da bracatinga, entre bracatingais manejados e formações secundárias nativas. \\ Foram realizados inventários florestais em 45 bracatingais (parcelas de $400 \mathrm{~m}^{2}$ ), com diferentes idades, e

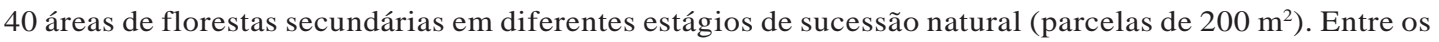 \\ resultados destaca-se que a estrutura demográfica da bracatinga e a diversidade das demais espécies apresentam \\ padrões bastante diferenciados entre os bracatingais e as florestas secundárias, especialmente nos primeiros \\ anos de desenvolvimento das duas comunidades vegetais. A expressiva diferença nestes padrões caracterizam \\ os bracatingais como paisagens manejadas, sendo estes dependentes da ação humana para sua formação e manutenção. \\ Palavras-chave: Manejo da paisagem, Domesticação e Legislação florestal.
}

\section{OCCURRENCE OF BRACATINGA (Mimosa scabrella BENTH.) IN BRACATINGA TRADITIONAL MANAGEMENT SYSTEM (BRACATINGAIS) AND SECONDARY FORESTS IN SANTA CATARINA STATE PLATEAU}

\begin{abstract}
Mimosa scabrella (Mimosa scabrella Benth.) is a multiple use forest species, typical from a mixed ombrophilous forest, asscociate to Atlantic forest biome. The objective of this study was to compare structure, vegetal diversity and occurrence of Mimosa scabrella among managed Mimosa scabrella woods and forest formations. Forest inventories were conducted in 45 plots ( $400-\mathrm{m}^{2}$ plots), at different ages, and 40 secondary forest areas at different stages of natural succession ( $200 \mathrm{~m}^{2}$ plots). The results show that there are different patterns in the demographic structure of Mimosa scabrella and species diversity between the bracatingais and secondary forests, particularly in the early years of both communities development. The significant difference in those patterns characterize the bracatingais as managed landscapes, which are strongly dependent on human action for its formation and maintanance.
\end{abstract}

Keywords: Domestication, Forest legislation and Landscape management.

\section{INTRODUÇÃO}

De acordo com Leach (1997), seria uma visão reducionista caracterizar a ampla diversidade de sistemas de produção de alimentos (e de outros produtos) do mundo apenas como sinônimo de agricultura. Nesse sentido, Clement (1999), propõe diversos níveis de domesticação de plantas e de paisagens, nos quais os sistemas produtivos são implementados. De acordo com esta ótica, a domesticação das espécies nem sempre segue o rumo da homogeneização genotípica em uma paisagem cultivada, mas envolve estratégias de adaptação promovidas pelo homem suas condições ambientais das paisagens em que é procedido o manejo das espécies de interesse (BALDAUF et al., 2009). Assim, a domesticação de plantas e paisagens pode ser entendida como um processo gradativo que parte das populações naturais de plantas em seu ambiente original até uma monocultura com um único genótipo, passando por

\footnotetext{
${ }^{1}$ Recebido em 31.03.2009 e aceito para publicação em 20.04.2011.

${ }^{2}$ Instituto Chico Mendes de Conservação da Biodiversidade, ICMBio, Brasil. E-mail: <steenbock.walter@gmail.com>.

${ }^{3}$ Universidade Federal de Santa Catarina, UFSC, Brasil. E-mail: <alesiminski@yahoo.com.br>, <afantini@cca.ufsc.br>e <msreis@cca.ufsc.br>.
} 
várias situações intermediárias ou diferentes intensidades de alterações genéticas e da paisagem (REIS et al., 2003).

No Brasil, a prática da agricultura, da silvicultura e da pecuária muitas vezes é realizada em paisagens não totalmente domesticadas, e nem envolve, necessariamente, a implantação de espécies totalmente domesticadas (CLEMENT, 1999). No sul do Brasil, no bioma Mata Atlântica, esta situação é evidenciada, por exemplo, no manejo agrossilvipastoril realizado nos faxinais (LOWEN-SAHR, 2007), na prática da agricultura de coivara (PERONI; HANAZAKI, 2002; SIMINSKI; FANTINI, 2007), nas estratégias de manejo de populações naturais do palmiteiro (Euterpe edulis) (REIS et al., 2000) e no manejo da samambaia-preta (Rhumora adiantiformis) por agricultores do nordeste do Rio Grande do Sul (BALDAUF et al., 2007), além de uma grande variedade de sistemas ainda não descritos em literatura científica.

Desconsiderando este contexto, bem como o potencial aspecto conservacionista dessa realidade, a Lei da Mata Atlântica, sancionada em 2006 (BRASIL, 2006), vetou qualquer possibilidade de manejo de populações naturais de espécies de interesse que não estejam caracterizadas como plantios. O plantio de espécies nativas, para fins comerciais, é atividade considerada legalizada tanto pela Lei da Mata Atlântica (BRASIL, 2006) quanto pelo Código Florestal (BRASIL, 1965). Os plantios florestais de espécies nativas, na área de abrangência do bioma Mata Atlântica, são regulamentados pela Instrução Normativa (IN) $n^{\circ}$ 08/ 2004, do Ministério do Meio Ambiente (BRASIL, 2004), que estabelece os mecanismos administrativos associados a informações de corte desses plantios, bem como pelo Decreto $n^{\circ}$ 6660/08 (BRASIL, 2008), que regulamenta a Lei da Mata Atlântica (BRASIL, 2006). Embora esses instrumentos legais não definam o que é um plantio de espécies nativas, em ambos está implícita a ideia de que uma formação florestal, para ser considerada como plantio, deve ter sido promovida a partir da implantação de mudas ou sementes em densidade ou espaçamento definido. $\mathrm{Na} \mathrm{IN} \mathrm{n}^{\circ}$ 08/2004 (BRASIL, 2004), é indicado que o produtor deve informar, no momento do corte, o "sistema de plantio" adotado, classificando-o em "monocultura” ou "plantio misto”. No Art 14 do Decreto n ${ }^{\circ}$ 6660/2008 (BRASIL, 2008), está disposto que o produtor deve informar, para o cadastro do plantio florestal, o número de espécimes de cada espécie plantada por intermédio de mudas ou a quantidade estimada de sementes de cada espécie no caso de sistema de plantio por semeadura. Essa concepção pressupõe que a ação humana do plantio deve ocorrer, necessariamente, a partir de uma intervenção intensa na paisagem (para a retirada da vegetação original, formação das covas e plantio de sementes ou mudas em espaçamento definido) e pela implantação de uma ou poucas espécies.

Na região noroeste do planalto catarinense, em assentamentos de reforma agrária, quase a metade da renda financeira das famílias assentadas (49,1\%, em média) é proveniente do manejo de bracatingais, formações florestais em que a bracatinga (Mimosa scabrella Benth.) é a espécie predominante, determinadas a partir de um conjunto de intervenções silviculturais (Figura 1) (STEENBOCK, 2009). Os bracatingais ocupam, em média, 24,6 \% da área dos assentamentos da região e, em função da preponderância do seu manejo como principal fonte de renda e de peculiaridades dos sistemas produtivos locais, este manejo contribui, de forma expressiva, para a manutenção de cobertura florestal nativa em 61 \% da área dos assentamentos (STEENBOCK, 2009). Entretanto, como em última análise o manejo de bracatingais não inclui a abertura de covas e não determina formações em densidade definida ou em linhas de plantio, esta prática é considerada atualmente ilegal.

Os agricultores da região reconhecem e distinguem o processo de formação e desenvolvimento dos bracatingais em relação a formações florestais secundárias (capoeiras), onde não houve ação humana na condução do processo sucessional. Tais paisagens são visualmente muito diferentes. Assim, por hipótese, essas duas paisagens florestais devem ser distintas em termos de estrutura e diversidade vegetal, em função das intervenções silviculturais implementadas nos bracatingais. Nesse contexto, os bracantigais seriam caracterizados como artefatos humanos, produtos de uma estratégia de domesticação.

Considerando a importância econômica e social do manejo de bracatingais na região noroeste do planalto catarinense, bem como a relação dos bracatingais com a conservação da cobertura florestal, é mister que sejam realizados estudos que possam avaliar se eles podem ser caracterizados como artefatos humanos e não como florestas nativas propriamente ditas. 
Fonte: STEENBOCK, 2009.

Source: STEENBOCK, 2009.

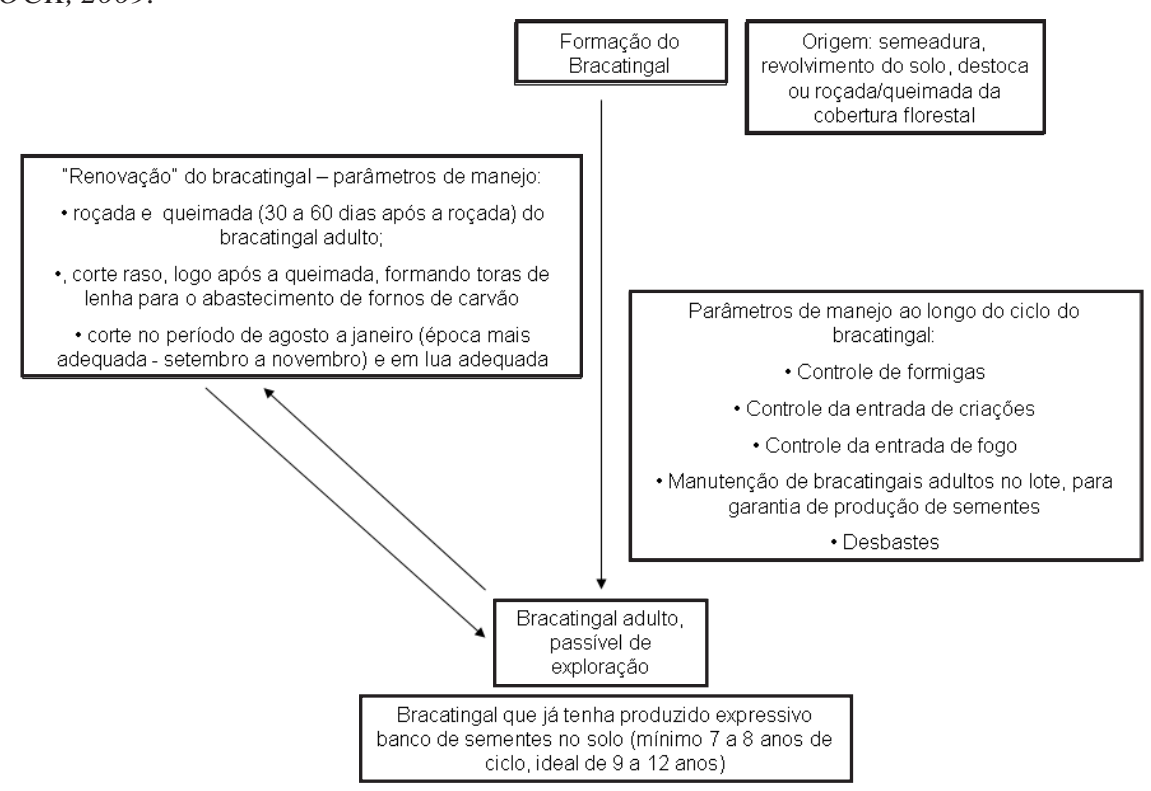

Figura 1 - Parâmetros de manejo de bracatingais considerados adequados por agricultores de assentamentos de reforma agrária da região noroeste do planalto catarinense (Steenbock, 2009).

Figure 1 - Management parameters of bracatingais considered suitable by farmers at rural settlements in northwestern Santa Catarina state Plateau.

Assim, o objetivo deste trabalho foi comparar as características de estrutura, a ocorrência da bracatinga e a diversidade vegetal entre bracatingais manejados em assentamentos de reforma agrária na região noroeste do planalto catarinense e formações secundárias nativas em que não houve intervenções silviculturais conduzindo o processo de sucessão.

\section{MATERIAL E MÉTODOS}

\subsection{Inventários para caracterização dos bracatingais}

Foram estudados 45 bracatingais, com idade entre 2 e 20 anos, selecionados a partir da indicação de agricultores de assentamentos de reforma agrária localizados nos Municípios de Calmon e Matos Costa (assentamentos Putinga, Jangada, Treze de Outubro e São Roque), região de ocorrência da Floresta Ombrófila Mista (FOM).

Nesses bracatingais, foram implantadas parcelas de $20 \times 20 \mathrm{~m}$, subdivididas em quatro subparcelas de 10 x 10 m (totalizando uma área amostrada de $18.000 \mathrm{~m}^{2}$ ). Para caracterizar a estrutura demográfica dos locais, foram avaliados o DAP (diâmetro a 1,3 m do solo) e a altura total (AT) de todos os indivíduos arbustivos e arbóreos (de todas as espécies) com DAP maior ou igual a $3 \mathrm{~cm}$. Em uma das subparcelas (10 x $10 \mathrm{~m})$, esses parâmetros foram avaliados em todos os indivíduos com altura maior ou igual a 1,5 m.

\subsection{Inventários para caracterização das formações florestais secundárias}

As áreas de formações florestais secundárias foram estudadas em 18 propriedades agrícolas nos Municípios de Caçador e Três Barras - SC, também região de ocorrência da Floresta Ombrófila Mista (FOM) (VELOSO et al., 1991). Foram amostradas 40 áreas onde os diferentes estágios da sucessão foram identificados na paisagem, através das características fitofisionômicas (KLEIN, 1980).

Em cada área selecionada, foi implantada uma parcela na parte central do bloco de formação secundária. Foram levantadas parcelas de 20 x 10 m, totalizando uma área de $8.000 \mathrm{~m}^{2}$. Foram mensurados o DAP e a AT de todos os indivíduos arbustivos e arbóreos com altura maior ou igual a 1,5 m, que foram também identificados quanto à espécie.

Revista Árvore, Viçosa-MG, v.35, n.4, p.845-857, 2011 


\subsection{Análise dos dados}

Neste artigo, frequência absoluta refere-se à percentagem de parcelas que apresentavam pelo menos um indivíduo de bracatinga; densidade refere-se ao número de indivíduos por hectare; abundância da bracatinga é a percentagem de indivíduos dessa espécie em relação ao número total de indivíduos de todas as espécies da parcela. A densidade e abundância de bracatinga em bracatingais foram também calculadas para indivíduos com DAP igual ou maior que $5 \mathrm{~cm}$, para discutir aspectos relacionados à legislação que regulamenta o manejo da espécie.

A partir dos dados das parcelas avaliadas, foram estimadas a média aritmética e o intervalo de confiança (á = 0,05) (STEEL; TORRIE, 1980) das variáveis DAP (diâmetro a 1,3 m), AT (altura total), AB (área basal). Para a interpretação dos dados, as parcelas foram agrupadas em classes de idade com intervalos de quatro anos, utilizando-se estatísticas descritivas para a análise e comparação dos dados. As comparações foram realizadas por meio dos intervalos de confiança (STEEL; TORRIE, 1980).

Para caracterizar a composição florística, todos os indivíduos foram identificados quanto à espécie. A identificação taxonômica foi realizada em campo quando inequívoca. Nos casos de dúvida, foi procedida a coleta de exsicatas compostas de partes vegetativas e, ou, reprodutivas, depositadas no acervo do Núcleo de Pesquisas em Florestas Tropicais (NPFT - UFSC). Nesse caso, a identificação foi feita no menor nível taxonômico possível com auxílio de bibliografia especializada (REITZ, 1965-1989; REIS, 1989-2007), seguindo o sistema do Angiosperm Phylogeny Group (APG), atualizado em APG II (2003), e confirmada por especialistas.

\section{RESULTADOS}

\subsection{Características estruturais}

Na Tabela 1, são apresentadas características estruturais das duas paisagens levantadas, destacando a ocorrência da bracatinga. Evidencia-se uma grande diferença entre os dois cenários analisados para a maioria das comparações realizadas. Mesmo em situações de alta variação entre as unidades amostrais (valores elevados de IC), as diferenças foram significativas.
A bracatinga ocorreu em 100 \% das áreas de bracatingais levantados, conforme o esperado, enquanto, nas áreas de florestas secundárias, este valor apresenta variação entre 13 e 100 \%, conforme o estádio de regeneração.

O bracatingal é caracterizado por uma altíssima densidade de indivíduos, predominantemente de bracatinga (87,6\%), na primeira fase de desenvolvimento ( 1 a 4 anos), que se reduz drasticamente com o tempo. Por sua vez, as áreas de formações florestais secundárias apresentam tendência de redução do número de indivíduos ao longo do tempo, porém não de forma tão abrupta, com maior ocorrência de indivíduos de bracatinga nas classes de idade de 13 a 16 e 17 a 20 anos (Tabela 1, Figura 2).

A abundância de indivíduos de bracatinga, em relação às demais espécies, é sempre maior que 80 \%, em bracatingais de 1 a 16 anos, reduzindo até 59,4\% em bracatingais mais velhos, de 17 a 20 anos (considerando os indivíduos com altura $\geq 1,5 \mathrm{~m}$ ). Se forem considerados somente indivíduos com DAP $\geq 5 \mathrm{~cm}$, a abundância da bracatinga é sempre maior que $90 \%$ em bracatingais de 5 a 16 anos, o que indica a homogeneidade temporal de crescimento das árvores das espécies que são recrutadas. Nos quatro primeiros anos de ciclo, a média desta abundância é bem mais baixa (33,9\%), seja porque uma parcela significativa desses bracatingais não apresenta nenhum indivíduo nesta faixa de diâmetro, seja porque são poucos.

Em florestas secundárias, a ocorrência da bracatinga é expressivamente menor do que nos bracatingais, e, quando a espécie ocorre, não chega a representar mais que $7 \%$ do total de espécies, em média (Tabela 1 ), com valor máximo encontrado de $18 \%$.

Os indivíduos de bracatinga também apresentam uma expressiva contribuição na composição da área basal nas áreas de bracatingais, formando mais de 80 \% daqueles com 1 a 16 anos. Com a evolução do ciclo, em bracatingais de 17 a 20 anos, a área basal representada pela bracatinga cai para 49,6 \% da área basal total. Nas florestas secundárias, a maior contribuição da bracatinga foi registrada justamente nesta classe de idade, representando esta espécie 35 \% da área basal total (Tabela 1). 
Tabela 1 - Parâmetros demográficos da ocorrência da bracatinga (Mimosa scabrella) em 45 bracatingais e 40 formações florestais secundárias avaliados de acordo com as classes de idade; onde: Bra - Bracatingal e Fsc.

Table 1 - Demographic parameters of bracatinga (Mimosa scabrella) occurence in 45 bracatingais and 40 secondary forest formation evaluated according to age classes. Bra - Bracatingais and FsC-Secondary forest.

\begin{tabular}{|c|c|c|c|c|c|c|c|c|c|}
\hline \multirow[t]{3}{*}{$\begin{array}{l}\text { Classe de idade } \\
\quad \text { (anos) }\end{array}$} & \multicolumn{2}{|c|}{$\begin{array}{c}\begin{array}{c}\text { Parcelas } \\
\left(\mathrm{n}^{\circ}\right)\end{array} \\
\end{array}$} & \multicolumn{2}{|c|}{$\begin{array}{c}\text { Frequência Absoluta } \\
\text { Bracatinga } \\
\end{array}$} & \multicolumn{2}{|c|}{$\begin{array}{c}\text { Densidade total } \\
\text { (ind/ha) }\end{array}$} & \multicolumn{3}{|c|}{$\begin{array}{c}\text { Densidade de } \\
\text { Bracatinga (ind/ha) } \\
\end{array}$} \\
\hline & \multirow[t]{2}{*}{$\overline{\mathrm{Bra}}$} & \multirow[t]{2}{*}{ Fsc } & \multirow[t]{2}{*}{ Bra } & \multirow[t]{2}{*}{ Fsc } & \multirow[t]{2}{*}{ Bra } & \multirow[t]{2}{*}{ Fsc } & \multicolumn{2}{|c|}{ Bra } & \multirow{2}{*}{$\begin{aligned} & \text { Fsc } \\
& \geq 1,5 \mathrm{~m} \\
&\end{aligned}$} \\
\hline & & & & & & & $\geq 1,5 \mathrm{~m}$ & $\geq 5 \mathrm{DAP}$ & \\
\hline 1 a $4 \mathrm{IC}$ & 13 & 6 & 100 & 33 & 34.302 & $8.133 \mathrm{~ns}$ & 30.060 & 806 & $100 *$ \\
\hline $\mathrm{C}(+/-)_{0,05}$ & & & & & 28.893 & 1.002 & 26.213 & 776 & 56 \\
\hline 5 a $8 I C$ & 16 & 4 & 100 & 33 & 6.470 & $7.267 \mathrm{~ns}$ & 5.355 & 2.432 & $50 *$ \\
\hline$(+/-)_{0,05}$ & & & & & 2.032 & 2.543 & 1.922 & 503 & 28 \\
\hline $\begin{array}{l}9 \text { a } 12 \mathrm{IC} \\
(+/-)_{0,05}\end{array}$ & 8 & 6 & 100 & 33 & $\begin{array}{c}1.962 \\
982\end{array}$ & $\begin{array}{c}6.533 * \\
1.991\end{array}$ & $\begin{array}{c}1.784 \\
944\end{array}$ & $\begin{array}{l}1.353 \\
568\end{array}$ & $\begin{array}{c}325 * \\
102\end{array}$ \\
\hline 13 a $16 \mathrm{IC}$ & 4 & 5 & 100 & 60 & 716 & $6.860 *$ & 663 & 663 & $483 n s$ \\
\hline$(+/-)_{0,05}$ & & & & & 377 & 4.035 & 353 & 353 & 213 \\
\hline 17 a $20 \mathrm{IC}$ & 4 & 5 & 100 & 100 & 883 & $\begin{array}{c}6.810 * \\
1.497\end{array}$ & $\begin{array}{l}525 \\
294\end{array}$ & $\begin{array}{l}525 \\
294\end{array}$ & $\begin{array}{c}440 n s 296 \\
296\end{array}$ \\
\hline 21 a $24 \mathrm{ICC}$ & - & 5 & - & 20 & - & 5.638 & - & - & 50 \\
\hline$(+/-)_{0,05}$ & & & & & & 2.122 & & & 14 \\
\hline $\begin{array}{l}>24 \mathrm{IC} \\
(+/-)_{0,05}\end{array}$ & - & 8 & - & 13 & - & $\begin{array}{l}5.228 \\
1.693\end{array}$ & - & - & $\begin{array}{l}50 \\
15\end{array}$ \\
\hline \multirow[t]{3}{*}{$\begin{array}{l}\text { Classe de idade } \\
\quad \text { (anos) }\end{array}$} & \multicolumn{2}{|c|}{$\begin{array}{c}\text { Parcelas } \\
\left(\mathrm{n}^{\circ}\right)\end{array}$} & \multicolumn{3}{|c|}{$\begin{array}{c}\text { Abundância da Bracatinga } \\
(\%)\end{array}$} & \multicolumn{2}{|c|}{$\begin{array}{c}\text { Área Basal } \\
\text { Total }\left(\mathrm{m}^{2} / \mathrm{ha}\right)\end{array}$} & \multicolumn{2}{|c|}{$\begin{array}{c}\text { Área Basal } \\
\text { Bracatinga(m²/ha) } \\
\end{array}$} \\
\hline & \multirow[t]{2}{*}{ Bra } & Fsc & \multicolumn{2}{|c|}{ Bra } & Fsc & \multirow[t]{2}{*}{ Bra } & \multirow[t]{2}{*}{ FsC } & \multirow[t]{2}{*}{ Bra } & \multirow[t]{2}{*}{ Fsc } \\
\hline & & & $\geq 1,5 \mathrm{~m}$ & $\geq 5 \mathrm{DAP}$ & $\geq 1,5 \mathrm{~m}$ & & & & \\
\hline 1 a $4 \mathrm{IC}$ & 13 & 6 & 87,6 & 33,9 & $1,2^{*}$ & 5,1 & $4,0 \mathrm{~ns}$ & 4,3 & $0,0^{*}$ \\
\hline$(+/-) 0,05$ & & & 12,5 & 28,4 & 0,7 & 4,9 & 2,8 & 4,4 & 0,0 \\
\hline $\begin{array}{l}5 \text { a } 8 \mathrm{IC} \\
(+/-) 0,05\end{array}$ & 16 & 4 & $\begin{array}{l}82,7 \\
13,4\end{array}$ & $\begin{array}{l}90,4 \\
13,6\end{array}$ & $\begin{array}{c}0,6 * \\
0,5\end{array}$ & $\begin{array}{c}23,9 \\
4,1\end{array}$ & $\begin{array}{c}9,2 * \\
2,3\end{array}$ & $\begin{array}{c}20,2 \\
3,9\end{array}$ & $\begin{array}{c}0,0 * \\
0,0\end{array}$ \\
\hline 9 a $12 \mathrm{IC}$ & 8 & 6 & 90,9 & 96,1 & $4,9 *$ & 16,7 & $14,0 \mathrm{~ns}$ & 15,9 & $1,6 *$ \\
\hline$(+/-) 0,05$ & & & 5,9 & 4,7 & 3,0 & 3,0 & 2,0 & 3,2 & 1,2 \\
\hline 13 a $16 \mathrm{IC}$ & 4 & 5 & 92,6 & 99,2 & $7,0 *$ & 16,4 & $24,2 \mathrm{~ns}$ & 14,9 & $5,5 \mathrm{~ns}$ \\
\hline$(+/-) 0,05$ & & & 34,3 & 35,8 & 5,2 & 7,9 & 9,8 & 7,1 & 3,7 \\
\hline $\begin{array}{c}17 \text { a } 20 \mathrm{IC} \\
(+/-) 0,05\end{array}$ & 4 & 5 & $\begin{array}{c}59,41 \\
8,7\end{array}$ & $\begin{array}{l}62,3 \\
18,9\end{array}$ & $\begin{array}{c}6,5^{*} \\
4,1\end{array}$ & $\begin{array}{l}36,7 \\
15,2\end{array}$ & $\begin{array}{c}28,3 \mathrm{~ns} \\
4,9\end{array}$ & $\begin{array}{c}18,2 \\
9,0\end{array}$ & $\begin{array}{c}9,9 \mathrm{~ns} \\
6,5\end{array}$ \\
\hline 21 a $24 I C$ & - & 5 & - & - & 0,9 & - & 36,1 & - & 2,5 \\
\hline$(+/-) 0,05$ & & & & & 0,6 & & 11,6 & & 1,7 \\
\hline $\begin{array}{l}>24 \mathrm{IC} \\
(+/-) 0,05\end{array}$ & - & 8 & - & - & $\begin{array}{l}1,0 \\
0,3\end{array}$ & - & $\begin{array}{l}39,9 \\
8,2\end{array}$ & - & $\begin{array}{l}3,5 \\
2,1\end{array}$ \\
\hline
\end{tabular}

ns-diferença não significativa em realção ao bracatingal (IC(+/-)0,05 - intervalo de confiança);* significativamente diferente em relação ao bracatingal.

ns - no significant difference in relation to bracatingal (IC(+/-)0,05 - confidence interval); * significantly different in relation to bracatingal.

Apesar de absolutamente dominante sobre os parâmetros estruturais nos bracatingais, a bracatinga, neste ambiente, apresenta algumas características diferenciadas conforme a classe de tamanho dos indivíduos. Na Tabela 1 também estão indicadas as médias dos parâmetros demográficos dos bracatingais, considerando os indivíduos com altura maior ou igual a $1,5 \mathrm{~m}(\geq 1,5 \mathrm{~m})$ e somente os indivíduos com DAP maior ou igual a $5 \mathrm{~cm}(\geq 5 \mathrm{~cm})$.

Nos quatro primeiros anos de ciclo dos bracatingais avaliados, a maioria dos indivíduos de bracatinga (97\%) não chegou a apresentar diâmetro à altura do peito (DAP) maior ou igual 

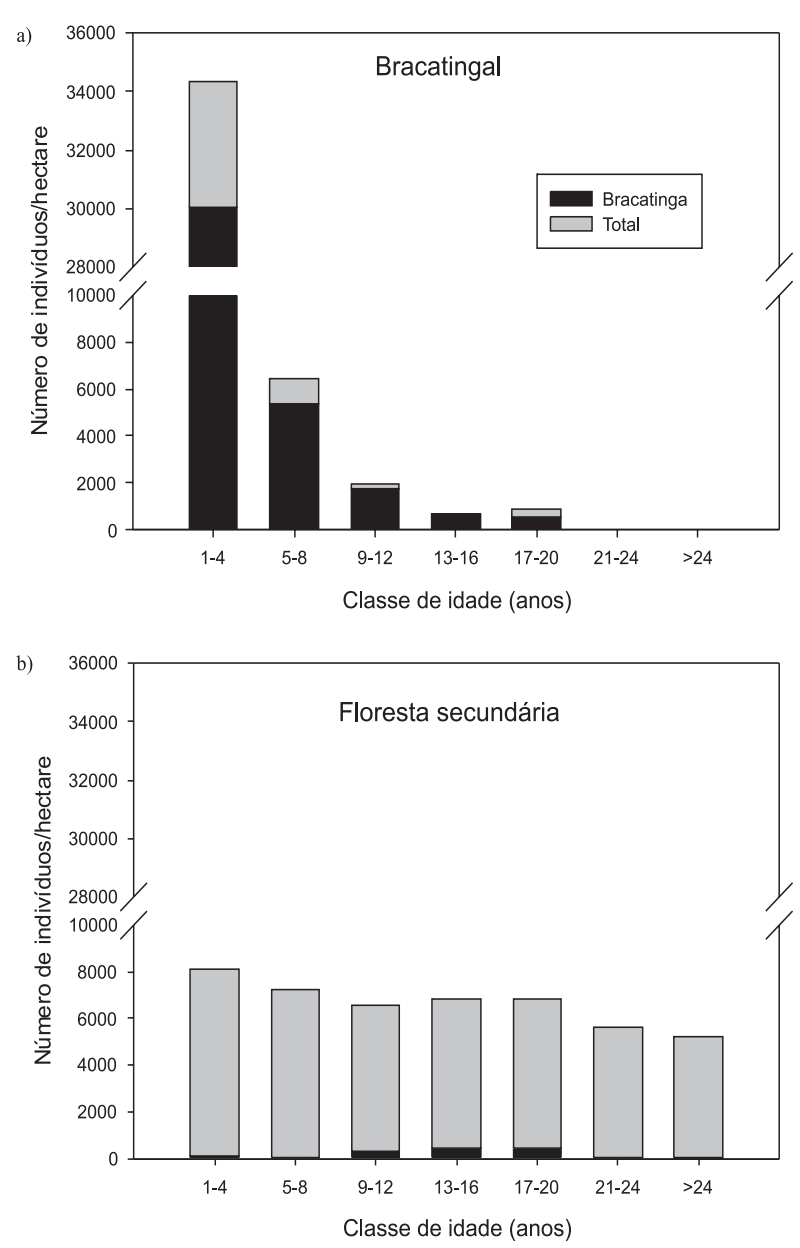

Figura 2 - Densidade (número de indivíduos por hectare) de bracatinga (Mimosa scabrella) em: (a) 45 bracatingais e (b) 40 formações florestais secundárias avaliados de acordo com as classes de idade.

Figure 2 - Density (number of individuals per hectare) of bracatinga (Mimosa scabrella) in (a) 45 bracatingais and (b) 40 secondary forest formation evaluated according to age class.

a $5 \mathrm{~cm}$. A proporção de indivíduos com DAP superior a $5 \mathrm{~cm}$ aumenta conforme a idade, representando no final do ciclo (17 a 20 anos), 100 \% dos indivíduos.

\subsection{Caracterização florística}

No conjunto de parcelas avaliadas, as áreas de formações secundárias apresentaram uma riqueza florística superior à dos bracatingais em todas as classes de tamanho avaliadas, chegando a quase quatro vezes maior quando considerado apenas os indivíduos com $\mathrm{DAP} \geq 5$ (Tabela 2).
A riqueza de espécies presente nos dois ambientes e suas respectivas frequências absolutas podem ser observadas na Tabela 2. Os bracatingais são caracterizados pelo reduzido número de espécies com frequência absoluta superior a 20 \%. Apenas cinco espécies, além da bracatinga, atingem este valor (Solanum variabile, Solanum mauritianum, Solanum pseudoquina, Ilex paraguariensis e Dicksonia sellowiana). Por sua vez, as áreas de floresta secundária apresentam 23 espécies com frequência absoluta superior a $20 \%$ (Tabela 2)

\section{DISCUSSÃO}

Em termos gerais, os padrões de densidade e abundância da bracatinga, avaliados neste estudo, apresentam semelhanças em relação aos padrões da espécie em bracatingais já estudados na região metropolitana de Curitiba. De acordo com Machado et al. (2006), naquela região o manejo de bracatingais cobre de 50.000 a 60.000 hectares e envolve um sistema tradicional de corte raso, queima, cultivo no primeiro ano (milho e feijão), pousio e novamente corte raso em torno dos 7 anos de idade, diferindo, em alguns aspectos, em relação ao sistema desenvolvido nos bracatingais objeto deste estudo (Figura 1). Entretanto, em bracatingais conduzidos daquela forma, Carpanezzi et al. (1988) identificaram de 2.129 a 2.636 plantas de bracatinga (DAP $\geq 5 \mathrm{~cm}$ ) por hectare em bracatingais de 4,5 a 7 anos, reduzindo-se esta densidade para 1.691 plantas por hectare em bracatingal de 9,5 anos; 815 plantas por hectare em bracatingal de 12 anos; e 509 plantas por hectare em bracatingal de 18 anos, em um padrão de redução populacional semelhante ao observado neste trabalho.

A partir de 5 até 16 anos de idade dos bracatingais, a abundância da bracatinga sempre foi superior a 90 \% em relação às demais espécies (considerando indivíduos com DAP $\geq 5 \mathrm{~cm}$ ). A baixa abundância de indivíduos que não são de bracatinga, nos bracatingais, é formada em sua maior parte por outras espécies pioneiras, como Solanum variabile, Solanum mauritianum e Solanum pseudoquina. Esta característica indica que o manejo do processo sucessional pelos agricultores favorece também a ocorrência de outras espécies pioneiras, ainda que em menor abundância que a bracatinga. 
Tabela 2 - Diversidade Florística e Frequências absolutas das espécies que ocorrem nos bracatingais e nas floresta secundárias, nos quatro níveis de análise avaliados, onde: Reg - indivíduos em regeneração, e”1,5 - indivíduos maiores que 1,5 m de altura, e"3 - indivíduos com DAP maior ou igual a $3 \mathrm{~cm}$ e e" 5 - indivíduos com DAP maior ou igual a $5 \mathrm{~cm}$.

Table 2 - Floristic diversity and absolute frequency of species in bracatingais and secondary forest, at the four evaluated

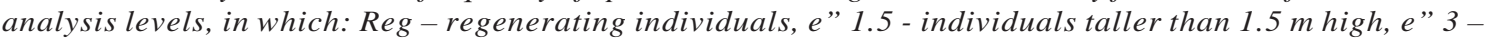
individuals with $D B H$ equal or greater than $3 \mathrm{~cm}$ and e" 5 -individuals with DBH equal or greater than 5

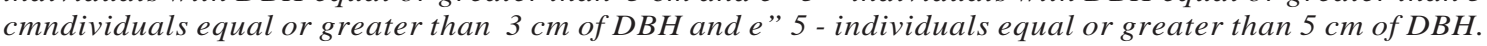

\begin{tabular}{|c|c|c|c|c|c|c|c|}
\hline \multirow[t]{2}{*}{ Diversidade Florística } & \multirow[b]{2}{*}{ Reg. } & \multicolumn{2}{|c|}{ Bracatingal } & & \multicolumn{3}{|c|}{ Floresta secundária } \\
\hline & & $\geq 1,5$ & $\geq 3$ & $\geq 5$ & $\geq 1,5$ & $\geq 3$ & $\geq 5$ \\
\hline Número de Famílias & & 22 & 17 & 17 & 45 & 43 & 37 \\
\hline Número de Espécies & & 50 & 31 & 24 & 133 & 116 & 95 \\
\hline Espécies (ordem alfabética) & & \multicolumn{6}{|c|}{ Frequências absolutas } \\
\hline Aegiphila sellowiana Cham. & & 7 & & & 5 & 3 & 3 \\
\hline Alchornea triplinervia (Spreng.) Müell. Arg. & & & & & 13 & 11 & 11 \\
\hline Allophylus edulis (A. St. Hil. \& al.) Radlk & & & & & 26 & 18 & 14 \\
\hline Allophylus guaraniticus (St. Hil.) Radlk & & & & & 34 & 29 & 22 \\
\hline Araucaria angustifolia (Bertol.) Kuntze & & 2 & 2 & 2 & 13 & 11 & 6 \\
\hline Asteraceae spp. & & 4 & & & & & \\
\hline Baccharis calvensces A.P. Candole & & & & & 11 & 8 & 6 \\
\hline Baccharis dentata ( Vell. ) G.M.Barroso & & & & & 3 & & \\
\hline Baccharis dracunculifolia DC & & 2 & & & 34 & 26 & 19 \\
\hline Baccharis elaeagnoides Steud. & & & & & 8 & 8 & 6 \\
\hline Baccharis erioclada DC. & & 9 & 9 & 7 & 5 & & \\
\hline Baccharis semiserrata DC. & & & & & 5 & 5 & 5 \\
\hline Baccharis sp. 1 & & & & & 3 & 3 & \\
\hline Baccharis sp. 2 & & & & & 3 & 3 & 3 \\
\hline Baccharis sp. 3 & & & & & 3 & 3 & \\
\hline
\end{tabular}

Baccharis sp. 4

Baccharis sp. 5

Baccharis trimera (Less.) DC.

Baccharis uncinella DC

$4 \quad 2$

Banara parviflora (A. Gray) Benth.

3

Banara tomentosa Clos.

Bastardiopsis densiflora (Hook. \& Arn.) Hassler

Cabralea canjerana (Vell) Mart.

Calyptrantes sp.

Campomanesia guazumifolia (Cambess.) O. Berg.

Campomanesia reitziana Legr.

Campomanesia xanthocarpa Berg

Capsicodendron dinisii (Schwacke) Occhioni

Capsicum cf. flexuosum Sendtn

Casearia decandra Jacq.

Casearia sylvestris Sw.

Cedrela fissilis Vell.

Celtis triflora (Klotszch.)Miq.

Cinnamomum amoenum (Nees) Kosterm.

Clethra scabra Pers.

Cordyline dracaenoides Kunth

Cryptocarya aschersoniana Mez

Cupania vernalis Camb.

Dalbergia frutescens Britton

Dicksonia sellowiana Hook

$\begin{array}{ll}3 & 3 \\ -3 & 3\end{array}$

Drimys brasiliensis Miers

Erythroxyllum deciduum S.

\begin{tabular}{|c|c|c|c|c|c|}
\hline & & & 5 & & \\
\hline & & & 16 & 11 & 11 \\
\hline & & & 32 & 24 & 19 \\
\hline 2 & 2 & & 3 & 3 & \\
\hline 4 & 2 & & 47 & 32 & 25 \\
\hline 2 & 2 & 2 & 24 & 11 & 11 \\
\hline & & & 26 & 21 & 14 \\
\hline & & & 3 & & \\
\hline & & & 5 & 5 & 5 \\
\hline 11 & 7 & 2 & 47 & 45 & 44 \\
\hline & & & 8 & 8 & 8 \\
\hline & & & 5 & 5 & 5 \\
\hline & & & 61 & 37 & 37 \\
\hline 2 & & & & & \\
\hline 22 & 31 & 31 & 5 & 5 & 5 \\
\hline & & & 11 & 11 & 11 \\
\hline 4 & & & 3 & 3 & \\
\hline
\end{tabular}


Tabela 2 - Cont.

Table 2 - Cont.

Diversidade Florística

Reg.
Re

Bracatingal $---\frac{-}{\text { Floresta secundária }}$

Eugenia chlorophylla O. Berg

Eugenia involucrata DC.

Eugenia pyriformis Camb.

Eugenia uniflora L.

Eupatorium serratum Spreng.

Eupatorium sp.

Eupatorium vauthierianum DC.

Ficus sp.

Gochnatia polymorpha (Less.) Cabrera.

Gymnanthes concolor Spreng

Hovenia dulcis Thumb. (exótica)

Ilex brevicuspis Reissek

Ilex dumosa Reissek

Ilex microdonta Reissek

Ilex paraguaiensis St. Hil.

Ilex theezans Mart. ex Reissek

Inga marginata Willd.

Inga virescens Bent.

Jacaranda micrantha Cham.

Jacaranda puberula Cham.

Lamanonia speciosa (Camb.) L.B.. Smith.

Lamanonia ternata Vell.

Leandra australis (Cham.) Cogn.

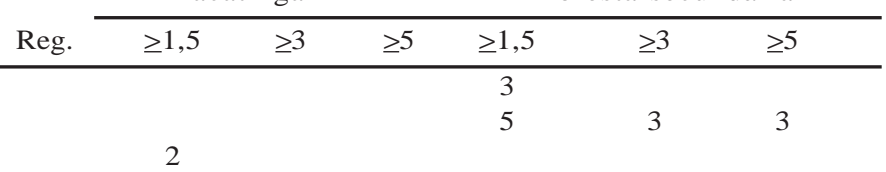

Lithraea brasiliensis March

Lonchocarpus campestris Mart. ex Benth

Lonchocarpus guilleminianus (Tul.) Malme

$\begin{array}{lll}3 & 3\end{array}$

Luehea divaricata Mart.

Machaerium paraguariensis Hassler

Machaerium stiptatum (DC.) Vog.

Manihot grahami Hook.

Matayba elaeagnoides Radlk

Maytenus ilicifolia Mart. ex Reiss

Miconia cinerascens Miq.

Miconia sp.

Mimosa scabrella Benth

Molinedia sp.

Mosiera prismatica (D. Legrand) Landrum

Myrcia guianensis (Aubl.) DC.

Myrcia multiflora (Lam.) DC.

Myrcia palustris DC.

Myrcia rostrata DC.

Myrcianthes pungens (Berg) Legr.

Myrciaria tenella (DC.) Berg.

Myrsine cf. lancifolia Mart.

Myrsine coriacea (Swartz) R. Brown ex Roemer \&Schultz

Myrsine umbellata Mat Ex. DC.

Myrtaceae spp. 3

$\begin{array}{llll}3 & 3 & \\ 3 & 3 & 3\end{array}$

Myrtaceae spp. 5

Myrtaceae spp. 6

Nectandra lanceolata Nees et Mart. ex Nees

Nectandra megapotamica Mez.

4

$\begin{array}{ll}2 & 18 \\ & 3\end{array}$

2

3
11

3
11

5

2

$\begin{array}{llll}5 & 5 & 3\end{array}$

$\begin{array}{llllll}22 & 7 & 7 & 47 & 34 & 25\end{array}$

$\begin{array}{lllll}4-2 & 13 & 11 & 11\end{array}$

$\begin{array}{lll}4 & 2 & 2\end{array}$

$\begin{array}{llll}21 & 16 & 17\end{array}$

$\begin{array}{llllll}2 & 2 & 2 & 24 & 18 & 19\end{array}$

$\begin{array}{llll}2 & 13 & 13 & 6\end{array}$

$\begin{array}{ccc}13 & 3 \\ 2 & 3\end{array}$

$\begin{array}{llllll}9 & 2 & 2 & 32 & 24 & 14\end{array}$

$2 \quad 3 \quad 3$

11

11

13

8

18

18

66

2

$\begin{array}{lllccc}100 & 89 & 84 & 45 & 37 & 36\end{array}$

$\begin{array}{ccc}3 & 3 & \\ 16 & 13 & 14\end{array}$

$$
3
$$

8

3

$\begin{array}{lllrcc}13 & 9 & 7 & 53 & 45 & 33 \\ & & & 16 & 13 & 8\end{array}$

2

$\begin{array}{llll}5 & 5 & 5\end{array}$

$\begin{array}{lll}5 & 5 & 5 \\ 3 & 3 & 3\end{array}$

$16 \quad 16 \quad 16$

13

Revista Árvore, Viçosa-MG, v.35, n.4, p.845-857, 2011 
Tabela 2 - Cont.

Table 2 - Cont

Reg.

$\begin{array}{llll}\geq 1,5 & \geq 3 \quad \geq 5 \quad \geq 1,5\end{array}$

Ocotea diospyrifolia (Meisn.) Mez

Ocotea porosa (Nees \& C. Mart.) Barroso

Ocotea puberula (Rich.) Nees

Ocotea pulchella Mart.

Ocotea sp. 2

Persea major (Nees) L. E. Kopp

Persea sp.

Picramnia parvifolia Engl.

Piptocarpha angustifolia Dusén ex Malme

Piptocarpha tomentosa Baker.

Podocarpus lambertii Klotzsch

Prunus myrtifolia (l.) Urb.

Psidium cattleyanum Sabine

$\begin{array}{cccc}11 & 11 & 9 & 18 \\ 2 & 2 & 2 & 29 \\ & & & \\ & & & \\ 15 & 15 & 9 & 16 \\ 18 & 18 & 11 & \\ 2 & & \end{array}$

Psychotria sp.

Psychotria suterella Müll. Arg.

Randia armata (Sw.) DC

Rollinia rugulosa Schl.

Roupala asplenioides Sleumer

Roupala cf. brasiliensis Klotzsch

Ruprechtia laxiflora Meisn.

Sapium glandulatum (Vell.) Pax.

Schefflera morototoni (Aubl.) Maguire, Stey. \& Frod

Schinus molle L.

Schinus terebinthifolius Raddi

Scutia buxifolia Reissek.

Sebastiana brasiliensis Spreng.

Sebastiana spp.

Sebastiania commersoniana (Baillon) L.B. Smith \& R.J.Downs

Solanaceae spp. 1

Solanum diflorum Vell.

Solanum mauritianum Scopoli

Solanum pseudoquina A.St.-Hil

Solanum sanctae-catharinae Dunal

Solanum sp.2

Solanum variabile Mart.

Sorocea bomplandii (Bail.) Burg. Lanj \& Boer

Strychnos brasiliensis (Spreng.) Mart.

Styrax cf. acuminatum Pohl

Styrax leprosus Hook. \& Arn.

Syagrus romanzoffiana (Cham.) Glassman

Symplocos celastrina Mart.

Symplocos cf uniflora (Pohl) Benth.

Symplocos lanceolata (Mart.) A.DC.

Symplocos tenuifolia Brand

Trema micrantha (L.) Blume

Trichilia elegans A.Juss.

Vernonia discolor (Spreng.) Less.

Vernonia petiolaris DC

Vernonia sp. 1

Vernonia sp. 2

Weinmannia paulliniifolia Pohl ex Ser.

Xylosma pseudosalzmannii Sleumer.

Zanthoxylum hiemalis A. St. Hil

Zanthoxylum rhoifolia (Lam.) Engl.

\begin{tabular}{|c|c|c|c|}
\hline$\geq 1,5$ & $\geq 3$ & $\geq 5$ & \\
\hline 3 & 3 & 3 & \\
\hline 8 & 8 & 8 & \\
\hline 18 & 18 & 18 & \\
\hline 58 & 58 & 58 & \\
\hline 29 & 29 & 29 & \\
\hline 3 & 3 & 3 & \\
\hline 3 & 3 & 3 & \\
\hline 3 & 3 & 3 & \\
\hline 5 & 5 & 5 & \\
\hline 16 & 16 & 16 & \\
\hline 8 & 8 & 8 & \\
\hline 8 & 5 & 5 & \\
\hline 5 & & & \\
\hline 3 & 3 & 3 & \\
\hline 11 & 3 & 3 & \\
\hline 5 & & & \\
\hline 11 & 5 & 3 & \\
\hline 37 & 32 & 25 & \\
\hline 8 & 8 & 8 & \\
\hline 3 & & & \\
\hline 5 & 3 & & \\
\hline 55 & 47 & 42 & \\
\hline 3 & 3 & 3 & \\
\hline 13 & 5 & 5 & \\
\hline 32 & 21 & 22 & \\
\hline \multirow[t]{2}{*}{3} & 3 & 3 & \\
\hline & 13 & 11 & 8 \\
\hline \multicolumn{4}{|l|}{3} \\
\hline 18 & 16 & 14 & \\
\hline 8 & 3 & 3 & \\
\hline 3 & & & \\
\hline 8 & 8 & 3 & \\
\hline 3 & 3 & & \\
\hline 3 & 3 & 3 & \\
\hline 5 & 5 & 3 & \\
\hline 11 & 11 & 11 & \\
\hline 3 & 3 & & \\
\hline 8 & 8 & 8 & \\
\hline 3 & 3 & & \\
\hline 5 & 5 & 5 & \\
\hline \multicolumn{4}{|l|}{3} \\
\hline \multicolumn{4}{|l|}{5} \\
\hline 18 & 16 & 14 & \\
\hline 5 & 5 & 3 & \\
\hline 8 & 3 & & \\
\hline \multicolumn{4}{|l|}{3} \\
\hline 5 & 3 & 3 & \\
\hline 5 & 3 & 3 & \\
\hline 13 & 11 & 6 & \\
\hline 50 & 29 & 22 & \\
\hline
\end{tabular}


Embora as espécies pioneiras se constituam na maior parcela dos indivíduos dos bracatingais, nessas formações há regeneração, no subbosque, de 50 espécies pertencentes a 22 famílias botânicas e a diferentes grupos ecológicos. O número de espécies do subbosque vai reduzindo-se na medida em que se consideram indivíduos de diâmetro cada vez maior, independentemente da idade dos bracatingais. Tal situação indica o padrão sucessional dos bracatingais, praticamente homogêneos de indivíduos de bracatinga e algumas outras espécies pioneiras na formação do dossel, porém possibilitando maior diversidade de indivíduos jovens em regeneração.

A única espécie não pioneira encontrada nos bracatingais, cujos indivíduos apresentavam DAP superior a $5 \mathrm{~cm}$, foi o xaxim (Dicksonia selowiana). A ocorrência desta espécie, com elevados valores de DAP (maiores que $15 \mathrm{~cm}$ ), contudo, indica que a regeneração da espécie não ocorreu a partir da formação dos bracatingais, mas sim que populações da espécie ocorriam antes da sua formação e se mantiveram mesmo após a queimada.

Os padrões de densidade e abundância de espécies dos bracatingais estudados são muito diferentes destes padrões em formações florestais da sucessão secundária típicas da Floresta Ombrófila Mista. Essas diferenças são resumidas na Tabela 3. A composição florística das formações florestais secundárias, conforme descrito neste estudo, apresenta semelhança em nível taxonômico na cronossequência com diferentes levantamentos nas regiões sul. Entre os gêneros que se destacam como os mais frequentes na Floresta Ombrófila Mista estão Baccharis, Casearia, Chethra, Ilex, Solanum, Nectandra,
Ocotea, Myrsine, Matayba, Piptocarpha, Sapium, Vernonia, Allophylus, Zanthoxylum e Capsicodendron (RONDON NETO et al., 2002; PEZZATTO et al., 2003; NARVAES et al., 2005; RAMOS; BOLDO, 2007).

Nas florestas secundárias aqui estudadas, ocorre um número significativo de espécies com alta frequência absoluta, comparando-se com os bracatingais. Além disso, essas espécies estão inseridas em diferentes grupos ecológicos, diferentemente do que ocorre nos bracatingais, onde a maioria das espécies com frequência absoluta maior que 20 \% pertence ao grupo ecológico das pioneiras.

Na floresta secundária, o processo sucessional pode ser caracterizado pela redução tanto de espécies quanto de indíviduos arbóreos do grupo de espécies pioneiras, e pelo estabelecimento de espécies que ocorrem em estádios sucessionais avançados (SILVA et al., 2004). Nos bracatingais aqui avaliados, mesmo de ciclos mais longos, esta situação não foi observada.

A comparação entre a ocorrência da bracatinga nos bracatingais conduzidos de forma tradicional e nas formações secundárias (Tabela 3) permite concluir que é o conjunto de parâmetros de manejo, adotados na condução dos bracatingais, que os tornam mais homogêneos, com elevada abundância da bracatinga e baixa diversidade vegetal. Essas características aproximam os bracatingais mais à condição de um plantio do que de uma floresta formada a partir da sucessão secundária, reforçando a intencionalidade na promoção da espécie neste tipo de formação.

Tabela 3 - Diferenças estruturais entre bracatingais e florestas secundárias, diagnosticadas a partir da avaliação demográfica e de diversidade vegetal em 45 bracatingais e 40 formações florestais secundárias da Floresta Ombrófila Mista.

Table 3 - Structural differences between bracatingais and secondary forests diagnosed from demographic assessement and vegetal diversity in 45 bracatingais and 40 secondary forest formation in Mixed Ombrophylous Forest.

Bracatingais

A densidade total de indivíduos é, em média, superior a 30.000 indivíduos por hectare, em bracatingais de 1 a 4 anos.

A bracatinga representa mais de 80 \% dos indivíduos, em bracatingais de 1 a 16 anos.

A densidade total de indivíduos é expressivamente reduzida ao longo do tempo, sendo, em bracatingais de 17 a 20 anos, de apenas $2,5 \%$ do total de indivíduos que ocorriam no início do ciclo.

A bracatinga está presente em 100 \% dos bracatingais.

Há um reduzido número de espécies, além da bracatinga, nos bracatingais. Neste estudo, apenas 5 espécies ocorreram em mais de $20 \%$ dos bracatingais avaliados, quase todas de caráter pioneiro.
Florestas secundárias

A densidade total de indivíduos é, em média, em torno de 8.000 indivíduos por hectare, em formações de 1 a 4 anos.

A percentagem da bracatinga nunca é superior a $18 \%$ em florestas secundárias de 1 a 16 anos.

A densidade total de indivíduos varia na ordem de 5.000 a 8.000 indivíduos por hectare ao longo do processo sucessional, em florestas de 1 a 20 anos de idade.

Em florestas jovens, nem sempre a bracatinga ocorre, sendo mais comum sua ocorrência em estágios intermediários da sucessão.

Maior diversidade de espécies, relativamente aos bracatingais, nas florestas secundárias. Neste estudo, 23 espécies ocorreram em mais de $20 \%$ das florestas avaliadas, de diferentes grupos ecológicos.

Revista Árvore, Viçosa-MG, v.35, n.4, p.845-857, 2011 
Outro aspecto que ratifica a diferença entre os bracatingais e as florestas secundárias nativas é a falta de compatibilidade entre os parâmetros que definem legalmente os estágios inicial, médio e avançado de regeneração de uma floresta nativa do bioma Mata Atlântica e essas características nos bracatingais. Em Santa Catarina, estes parâmetros são legalmente instituídos pela Resolução $n^{\circ}$ 04/94, do CONAMA (BRASIL, 1994), reeditada pela Resolução n ${ }^{\circ}$ 388/07, do CONAMA (BRASIL, 2007).

Em uma floresta nativa, a citada Resolução propõe que a altura média do dossel e a área basal é sempre crescente, na medida em que a floresta avança em seu processo sucessional. Conforme os resultados deste trabalho (Tabela 1), fica claro que parâmetros como a área basal dos bracatingais, entre outros, são condicionados por atividades de manejo, não tendo a idade do bracatingal como condicionante. Assim, se este parâmetro fosse utilizado para caracterizar os estágios sucessionais dos bracatingais, há áreas que, aos 3 anos de idade, seriam consideradas florestas em estágio avançado de regeneração (área basal $>15 \mathrm{~m}^{2} / \mathrm{ha}$ ), assim como bracatingais que, aos 12 anos de idade, seriam considerados em estágio médio de regeneração (área basal entre 8 e $15 \mathrm{~m}^{2} /$ ha). Há ainda bracatingais com mais de 15 anos que seriam considerados em estágio inicial de regeneração (área basal $<8$ m²/ha).

Em Santa Catarina, desde 2002 até a edição da Lei da Mata Atlântica, em 2006 (BRASIL, 2006), vigorou a Resolução CONAMA n ${ }^{\circ}$ 310/02 (BRASIL, 2002). De acordo com este instrumento legal, o manejo da bracatinga poderia ser efetivado por meio de corte seletivo, de no máximo 40 \% dos indivíduos de bracatinga com DAP maior que $5 \mathrm{~cm}$, em formações em estágio médio de regeneração. Como esta proposta de manejo não possibilitava a renovação dos bracatingais, não se adapta às condições de manejo dos bracatingais estudados. Esta Resolução possibilitava ainda a renovação, através do corte raso, de formações florestais com mais de 2.500 indivíduos de bracatinga por hectare, com DAP maior que $5 \mathrm{~cm}$. Todavia, entre os 45 bracatingais avaliados neste estudo, apenas 12 apresentam esta condição em variadas idades e diferentes combinações de parâmetros de manejo.

Recentemente, a Lei da Mata Atlântica (BRASIL, 2006) criou um dispositivo legal capaz de considerar a possibilidade de regulamentação do manejo tradicional de bracatingais ao definir, em seu Artigo 28, que é possível o corte, a supressão ou o manejo de espécies arbóreas pioneiras nativas em fragmentos florestais em estágio médio de regeneração, se sua presença for superior a $60 \%$ em relação às demais espécies. Entretanto, o Decreto $n^{\circ}$ 6.660/2008 (BRASIL, 2008), que regulamenta a citada Lei, define, em seu Artigo 36, Inciso II, que o volume e a intensidade de tal corte não podem descaracterizar o estágio médio de regeneração do fragmento. Uma vez que a área basal é um dos parâmetros que definem o estágio sucessional (BRASIL, 1994, 2007), é praticamente óbvio que o corte de $60 \%$ ou mais das árvores de um fragmento irá reduzir, significativamente, esta área basal, descaracterizando, muito provavelmente, o estágio médio de regeneração. Dessa forma, o Decreto $n^{\circ}$ 6.660/2008 (BRASIL, 2008) inviabiliza, potencialmente, um dispositivo legal instituído na Lei que ele regulamenta.

Atualmente, portanto, a legislação ambiental brasileira carece de instrumentos que regulamentem o manejo tradicional dos bracatingais, ainda que não sejam, definitivamente, produto da sucessão secundária natural ou florestas nativas. Conforme os resultados deste trabalho indicam, a aplicação dos parâmetros de manejo dos bracatingais resulta em parâmetros demográficos e de diversidade muito diferentes do que em florestas secundárias típicas. De acordo com a classificação proposta por Clement (1999), é possível considerar que um bracatingal está na categoria de paisagem manejada, na qual as populações da espécie, gradativamente, vêm sendo selecionadas pelas características do sistema de manejo adotado, apresentando atualmente domesticação incipiente.

A restrição da legislação ambiental ao manejo dos bracatingais implica a inviabilidade de um dos mais importantes usos econômicos da terra na região, com importante implicação social para os agricultores locais. Quando confrontados com a falta de alternativa para o uso tradicional da terra, os agricultores, e outros proprietários rurais, buscam a sua substituição. Em Santa Catarina, particularmente na região do Planalto, a principal opção desses agricultores é a substituição de vegetações nativas por plantios de monoculturas de pínus e eucaliptos, como demonstra Siminski (2009). Esse uso alternativo da terra tem um duplo impacto na redução da biodiversidade: por um lado, reduz as áreas cobertas com ecossistema nativos e, por outro, aumenta o grau de fragmentação e isolamento das

Revista Árvore, Viçosa-MG, v.35, n.4, p.845-857, 2011 
formações vegetais nativas remanescentes, ou seja, trazem resultados opostos àqueles que os legisladores aparentemente pretendiam.

\section{CONCLUSÃO}

Os resultados deste trabalho indicam que, caso as intervenções praticadas intencionalmente para a formação dos bracatingais não ocorram, os padrões demográficos da bracatinga e a diversidade das demais espécies resultam em estruturas bastante diferenciadas. A expressiva diferença nesses padrões, entre os bracatingais e as florestas secundárias da região de domínio da Floresta Ombrófila Mista, caracteriza os primeiros como paisagens manejadas, desde o início do ciclo e expressivamente dependentes da ação humana para sua formação e manutenção na forma em que se constituem.

Outrossim, como a existência dos bracatingais depende de intervenções antrópicas desde o início do ciclo, a formação e conservação do bracatingal é uma opção de uso do solo, e não uma cobertura vegetal nativa com especial necessidade de proteção.

A conceituação de formações florestais com mais de 80 \% de indivíduos de bracatinga - considerando indivíduos com altura maior ou igual a 1,5 m e, ou, DAP maior ou igual a $5 \mathrm{~cm}$ - formadas a partir de parâmetros de manejo promovidos por agricultores familiares e comunidades tradicionais, como artefatos humanos (e não como florestas secundárias nativas), pode ser um critério simples e eficaz para caracterizar a possibilidade legal de manejo dessas formações, de forma semelhante ao que ocorre em relação aos plantios florestais.

\section{AGRADECIMENTOS}

Ao Núcleo de Pesquisas em Florestas Tropicais da Universidade Federal de Santa Catarina e aos acadêmicos Carla Suntii, Rodrigo José Fávero, Delmar Dresch, Katia Inês Klaus Gonçalves e Giuliano Dragone de Andrade, da Universidade do Contestado, pelo apoio logístico; ao CNPq, pela concessão de bolsas de Doutorado e pelo apoio ao trabalho (Edital CNPQ 020/ 2005); aos Drs. Ademir Reis, Ademir Roberto Ruschel e Marcos Sobral, pelo auxílio na identificação do material botânico.

Revista Árvore, Viçosa-MG, v.35, n.4, p.845-857, 2011

\section{REFERÊNCIAS}

APG II. An update of the Angiosperm Phylogeny Group classification for the orders and families of flowering plants: APG II. Botanical Journal of the Linnean Society, v.141, n.4, p.399-436, 2003.

BALDAUF, C. et al. Interações entre pessoas, plantas e paisagens. In: CLEMENT, C. R. Origem e domesticação das plantas cultivadas. Manaus/Florianópolis: INPA/UFSC, 2009. No prelo

BRASIL. Lei no 4471, de 15 de setembro de 1965. Diário oficial da União, 16 de set. de 1965.

BRASIL. Conselho Nacional de Meio Ambiente. Resolução $n^{\circ}$ 04, de 4 de maio de 1994. Diário Oficial da União, 5 de maio de 1994.

BRASIL. Conselho Nacional de Meio Ambiente. Resolução $n^{\circ}$ 310, de 05 de julho de 2002. Diário Oficial da União, 6 de jul. de 2002.

BRASIL. Ministério do Meio Ambiente. 2004. Instrução Normativa $n^{\circ} \quad 008 / 2004$. Disponível em http: www.mma.gov.br. Acesso em 28 de dez. 2008.

BRASIL. Lei n ${ }^{\circ}$ 11428, de 22 de dezembro de 2006. Diário Oficial da União, 23 de dez. 2006.

BRASIL. Conselho Nacional de Meio Ambiente. 2007. Resolução n ${ }^{\circ}$ 388, de 23 de fevereiro de 2007. Diário oficial da União, 24 de fev. de 2007.

BRASIL. 2008. Decreto ${ }^{\circ} 6660$, de 21 de novembro de 2008. Diário Oficial da União, 24 de ago. de 2008.

CARPANEZZI, A. A. et al. Manual técnico da bracatinga (Mimosa scabrella Bentham). Colombo: Embrapa-CNPF, 1988. 70p.

CLEMENT, C. R. 1492 and the loss of Amazonian crop genetic resources. I. the relation between domestication and human population decline. Economic Botany, v.53, n.2, p.188-202, 1999.

LEACH, H. M. The terminology of agricultural origins and food production systems $-\mathrm{a}$ horticultural perspective. Antiquity, v.71, n.271, p.135-148, 1997. 
LOWEN-SAHR, C.; CUNHA, L. A. G. O significado social e ecológico dos faxinais: reflexões acerca de uma política agrária sustentável para a região da mata com araucária no Paraná. Emancipação, v.5, n.1, p.89-104, 2005.

MACHADO, S. A. et al. Dinâmica da distribuição diamétrica de bracatingais na região metropolitana de Curitiba. Revista Árvore, v.30, n.5, p.759768, 2006.

NARVAES, I. S.; BRENA, D. A.; LONGHI, S. J. Estrutura da regeneração natural em floresta ombrófila mista na floresta nacional de São Francisco de Paula, RS. Ciência Florestal, v.15, n.4, p.331-342, 2005.

RONDON NETO, R. M. et al. Análise florística e estrutural de um fragmento de floresta ombrófila mista montana, situado em Criúva, RS - Brasil. Revista Ciência Florestal, v.12, n.1, p.29-37, 2002.

Peroni, N.; Hanazaki, N. Current and lost diversity of cultivated varieties, especially cassava, under swidden cultivation systems in the Brazilian Atlantic Forest Agriculture, Ecosystems and Environment, v.92, p.171-183, 2002.

PEZZATTO, A. W. et al. Análise estrutural comparada entre floras arbóreas de fragmentos florestais ao longo da margem do reservatório de Salto Caxias PR. In: CONGRESSO DE ECOLOGIA DO BRASIL, 6., 2003, Fortaleza. Anais... Fortaleza: 2003. v.1. p.501-503.

RAMOS, A. J. K.; BOLDO, E. Diversidade florística e aspectos fitossociológicos de formações florestais em estágio sucessional secundário na floresta ombrófila mista, município de Caxias do Sul-RS. Revista Brasileira de Agroecologia, v.2, n.1, p. 111-116, 2007.

REIS, M. S. et al. Variacao genetica em populacoes naturais de Euterpe edulis Martius na Floresta Ombrofila Densa. Sellowia, v.49-52, p.131-149, 2000.

REIS, A. (Ed.) Flora ilustrada catarinense. Itajaí: Herbário Barbosa Rodrigues, 1989-2007.
REIS, M. S.; MARIOT, A.; STEENBOCK, W. diversidade e domesticação de plantas medicinais. In: SIMÕES, C. M. O. et al. (Orgs.) Farmacognosia - da planta ao medicamento. Florianópolis: Universidade Federal de Santa Catarina. Porto Alegre: Universidade Federal do Rio Grande do Sul, 2003. p.45-74.

REITZ, R. (Ed.). Flora ilustrada catarinense. Itajaí: Herbário Barbosa Rodrigues, 1965-1989.

SANTA CATARINA - Secretaria de Estado da Agricultura e Desenvolvimento Rural/EPAGRI. Projeto Inventário Florestal do Estado de Santa Catarina. 2005.

SILVA, N. R. S. et al. Composição florística e estrutura de uma floresta estacional semidecidual montana em Viçosa, MG. Revista Árvore, v.28, n.3, p.397-405, 2004.

SIMINSKI, A.; FANTINI, A. C. Roça-de-toco: uso de recursos florestais e dinâmica da paisagem rural no litoral de Santa Catarina. Ciência Rural, v.37, p.1-10, 2007.

SIMINSKI, A. Floresta do Futuro: conhecimento, valorização e perspectiva de uso das formações florestais secundárias no estado de Santa Catarina. Tese (Doutorado em Recursos Genéticos Vegetais) - Universidade Federal de Santa Catarina, Florianópolis, 2009.

STEEL, R. G. D.; TORRIE, J. H. Principles an procedures of statistics. A biometrical approach. 2.ed. New York: McGraw-Hill Book, 1980.633p.

STEENBOCK, W. Domesticação de bracatingais: perspectivas de inclusão social e conservação ambiental. 2009. 262f. Tese (Doutorado em Recursos Genéticos Vegetais) - Universidade Federal de Santa Catarina, Florianópolis, 2009.

VELOSO, H. P.; RANGEL FILHO, A. L. R. R.; LIMA, J. C. A. Classificação da vegetação brasileira, adaptada a um sistema universal. Rio de Janeiro: IBGE, 1991. 124p. 
